\title{
COMPARATIVE EVALUATION OF METHODS FOR SEPARATING GRAIN MOTH EGGS IN PRODUCTION OF TRICHOGRAMS
}

\author{
Gennadii Golub ${ }^{1}$, Oleh Marus ${ }^{1}$, Yaroslav Yarosh ${ }^{2}$, Natalja Karpiuk ${ }^{2}$ \\ ${ }^{1}$ National University of Life and Environmental Sciences of Ukraine, Ukraine; \\ ${ }^{2}$ Polissia National University, Ukraine \\ gagolub@ukr.net, marus_o@ukr.net, yaroslav.yarosh76@gmail.com,karpiuknat@gmail.com
}

\begin{abstract}
The method of separation of grain moth eggs, which are used for breeding the biological preparation Trichogramma, which allows obtaining the maximum number of large grain moth eggs from the total mass, which contains conglomerates, large and small eggs, is substantiated. After all, from large eggs of the grain moth, a stronger and more active generation of Trichogramma is revived, this is especially important in the royal production of the drug. When evaluating the methods of separating grain moth eggs into fractions, a pneumatic calibrator, an electric separator and a rotating disk were used. During experimental studies in the separation chamber of the pneumatic calibrator the axial fan created a horizontal airflow of $3.8 \mathrm{~m} \cdot \mathrm{s}^{-1}$, the electrodes of the electric separator were supplied with a voltage of $83 \mathrm{~V}$, and a rotating disk with a diameter of $650 \mathrm{~mm}$ was turned with the speed of $115 \mathrm{rpm}$. A certain number of grain moth eggs were selected from each fraction to measure their size and determine their volume (ellipsoid). The results of comparative experimental studies of each method for dividing grain moth eggs into three fractions demonstrated that the separation of conglomerates from the total mass is best performed by a pneumatic calibrator ( $80 \%$ of conglomerates fell into the first fraction). The electric separator and the rotating disk provided less than $60 \%$ of conglomerates to the first fraction. The results of the experimental studies showed that the integral probability of obtaining large grain moth eggs in the second container of a pneumatic calibrator was $49.9 \%$, an electric separator $-55.04 \%$, and a rotating disk $-63.54 \%$. Given that large grain moth eggs are best selected by a rotating disk, and conglomerates are best selected by a pneumatic calibrator, it is necessary to combine them by creating a two - stage calibrator (first select conglomerates with a pneumatic calibrator, and then separate large and small grain moth eggs with a rotating disk).
\end{abstract}

Keywords: pneumatic calibrator, electric separator, rotating disk.

\section{Introduction}

One element of organic production is the use of entomological drugs in biological plant protection. In Ukraine, one of the mass biological plant protection products used in agriculture is Trichogramma, which destroys pests at the egg stage.

Maintaining or improving the quality indicators of Trichogramma, especially in the uterine production of the drug, is carried out in several ways, namely: periodic use of eggs of natural hosts, collection of starting colonies of natural populations of Trichogramma, heterosis, introduction of the Trichogramma into diapause, feeding the trichogram with honey solution and using large grain moth eggs [1]. Chinese scientists [2] have long used oak silkworms (Antheraea pernyi) as host eggs for the production of Trichogramma dendrolimi). Waage and Lane [3] determined the effect of Mamestra brassicae egg size on fertility and sex distribution of Trichogramma Evanescens Westwood. It was found that at the beginning of egg-laying by Trichogramma females more males were hatched from eggs than females.

Greenberg et al. [4] determined the role of Trichogramma minutum Riley and Trichogramma pretiosum Riley, reared on Helicoverpa zea eggs, as parasitoids of the Mexican rice borer, Eoreuma loftini Dyar and sugarcane borer Diatraea saccharalis under laboratory and greenhouse conditions. Research results showed that Trichogramma minutum, reared on Helicoverpa zea eggs parasitized $52.5 \%$ of Mexican rice borer eggs Eoreuma loftini, compared to $50.3 \%$ for Trichogramma pretiosum. At the same time Trichogramma minutum on Helicoverpa zea eggs parasitized $42 \%$ of sugarcane borer eggs, compared to only $12.6 \%$ by Trichogramma pretiosum. These results show the potential use of Trichogramma to control sugarcane stalk borers in the field. An important role in Trichogramma production technology plays observing temperature regimes and humidity. The work [5] shows the effect of temperature on longevity and the ratio of sexes of Trichogramma individuals. Studies have shown that the optimum temperature values were in the range of 25 to $28^{\circ} \mathrm{C}$. The effect of non-ionizing ultraviolet radiation as a treatment method and its effect on parasitic rate and viability of Trichogramma adult individuals were also studied [6]. 
There are also known studies [7] to determine the influence of the size of grain moth eggs from the second to seventh generation on the quality indicators of Trichogramma: the level of search ability, the level of deformed individuals, the fecundity of Trichogramma females, the level of rebirth of individuals, the relative number of females and the fecundity of Trichogramma females. It was found that the size of grain moth eggs from the second to the seventh generations of Trichogramma had the greatest positive effect on the level of search ability, the level of deformed individuals and fecundity of females of Trichogramma. The influence of the size of grain moth eggs on the level of regeneration of individuals, the relative number of females and the fecundity of females of Trichogramma from the second to the seventh generations was not statistically significant.

The analysis of the research results showed that the qualitative indicators of Trichogramma determine the effectiveness of the drug, which, in turn, largely depends on the size of the grain moth eggs it was bred on. In this regard, the Trichogramma production technology includes selecting large grain moth eggs for further breeding of Trichogramma. In terms of their geometric dimensions, grain moth eggs are quite close to each other and therefore dividing them into fractions is not an easy task. In addition, grain moth eggs are living organisms, and therefore the ability to complicate the processes of their separation into fractions is limited by their deformation, which worsens their quality, and therefore Trichogramma refuses to use such eggs, trying to find better conditions for its future offspring.

To date, the pneumatic calibrator of grain moth eggs is known [8], which is used in production, and therefore the matter of using other types of calibrators to ensure the separation of grain moth eggs into fractions is relevant.

\section{Materials and methods}

A pneumatic calibrator with a horizontal air flow velocity of $3.8 \mathrm{~m} \cdot \mathrm{s}^{-1}$ [8], an experimental electric separator and an experimental rotating disk were used to determine the optimal method for separating grain moth eggs into three fractions (conglomerates, large and small). Speed hovering in the airflow of grain moth eggs was for large eggs from 1.7 to $1.8 \mathrm{~m} \cdot \mathrm{s}^{-1}$ and for small eggs from 1.6 to $1.7 \mathrm{~m} \cdot \mathrm{s}^{-1}$.

A batch of grain moth eggs was cleaned before conducting research, after which its composition was determined by the size of the eggs. It was found that the initial mass of grain moth eggs consisted of $28 \%$ of conglomerates, $34 \%$ of large and $38 \%$ of small eggs. The initial mass of grain moth eggs was divided into 3 parts of $10 \mathrm{~g}$ each for their subsequent separation in three ways. After dividing the grain moth eggs by each method into three fractions, a certain number of eggs were selectively taken from each fraction to measure their length and width, using the stereoscopic microscope MBS-10 type AC 3.850.005 RE. Based on these data, the volume of grain moth eggs was calculated, assuming that they are an ellipsoid in shape.

The process of separating grain moth eggs into fractions was carried out using a pneumatic calibrator - depending on the aerodynamic properties of eggs, an electric separator - depending on the electrostatic properties of eggs, and a rotating disk under the action of centrifugal forces (Fig. 1.).

a)

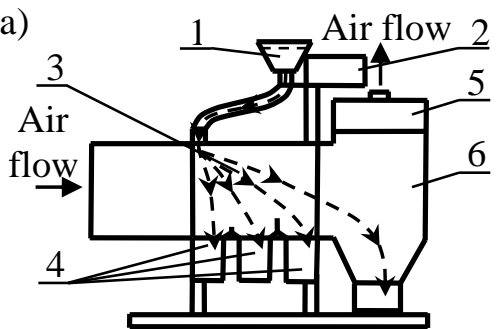

b)

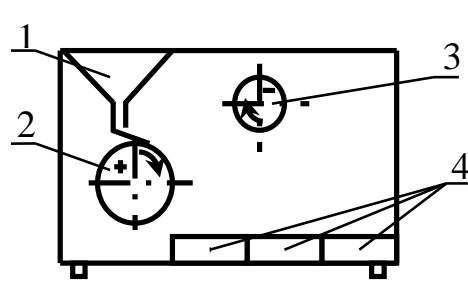

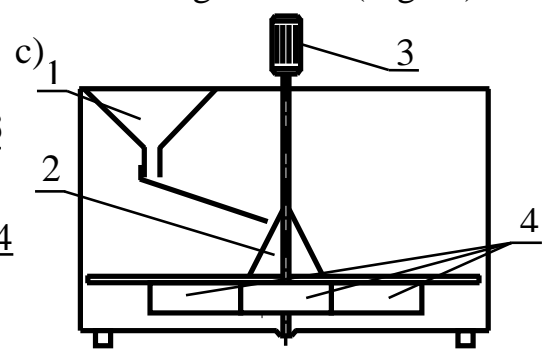

Fig. 1. Devices for separating grain moth eggs: a - pneumatic calibrator ( 1 - container; 2 - vibration unit; 3 - separation chamber; 4 - containers for grain moth eggs of various fractions; 5 - aspirator with a filtering element; 6 - cyclone separator); $b$ - electric separator ( 1 - container; 2,3 -drums; 4 - containers

for grain moth eggs of various fractions); c - rotating disk (1 - container; 2 - inclined guide cone, 3 - electric drive; 4 - containers for grain moth eggs of various fractions)

On the basis of the research of the Plant Protection Department of the All-Union Scientific Research Institute of Biological Methods of Plant Protection [9], it was found that the minimum volume of large 
grain moth eggs for the production of Trichogramma was $0.0247 \mathrm{~mm}^{3}$, respectively, if the volume was smaller, the eggs were classified as small.

The probability of selecting large grain moth eggs was determined by the integral probability $\operatorname{Im}(\%)$ that the size of grain moth eggs is in the range exceeding the minimum volume limit for large eggs $0.0247 \mathrm{~mm}^{3}$.

The experimental electric separator had a hopper; rotating drum-electrode and a fixed drumelectrode are connected to a DC source with a voltage of $83 \mathrm{~V}$. Grain moth eggs from the hopper fell on the outer surface of the rotating drum-electrode and then came under the action of an electrostatic field.

The experimental rotating disk had a hopper; horizontal rotating disk with a diameter of $650 \mathrm{~mm}$, which rotated at a speed of $115 \mathrm{rpm}$.

\section{Results and discussion}

The conducted studies on the division of grain moth eggs into three fractions using a pneumatic calibrator (Fig. 2) showed that the first fraction for conglomerates included $80 \%$ of conglomerates, $6 \%$ of large eggs and $14 \%$ of small ones. Getting into the first fraction of large and small eggs is explained by the fact that when conglomerates enter the bunker some of them break up or single eggs separate from conglomerates, which leads to a deterioration in statistics. In the first fraction, almost all conglomerates consisted of 3 or more eggs. The second fraction, where large grain moth eggs should be, also included a significant part of conglomerates, which accounted for $46 \%$, small eggs $-28 \%$, large ones $-26 \%$. This distribution of grain moth eggs in the second container shows that an increase in the air flow rate in order to reduce the number of small eggs will lead to an increase in the number of conglomerates, and a decrease in the air flow rate will lead to an increase in the number of small eggs. It was also found that in the second fraction during pneumatic calibration, almost all conglomerates consisted of 2 eggs. The third container included 70\% of small eggs, $26 \%$ of large eggs and $4 \%$ of conglomerates. The conglomerates that ended up in the third container consisted of two small eggs, and one egg from a pair could be empty or deformed. This distribution of grain moth eggs by fractions when using a pneumatic calibrator showed that it is necessary to conduct additional research to determine the optimal parameters of the device, especially it is necessary to pay attention to the size and installation location of receiving containers.

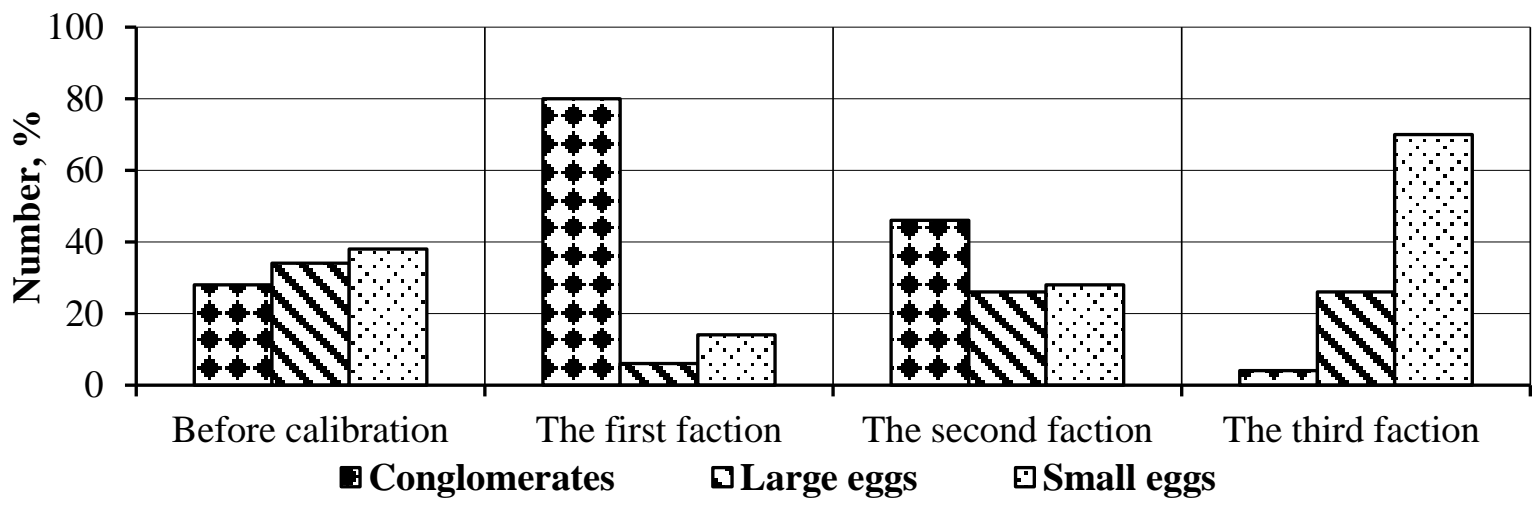

Fig. 2. Grain moth egg distribution diagram after pneumatic calibration

The probability that the volume of grain moth eggs meets the requirements for large eggs in the second container of the pneumatic calibrator was $49.9 \%$ (Fig. 3). In the integral probability graphs (Fig. $3,5,7)$, to the left of the vertical line, the probability of selecting small eggs is demonstrated, and to the right - the probability of selecting large grain moth eggs, considering the total number of grain moth eggs that fell into the second container.

In Fig. 4 the results of studies of the separation of grain moth eggs by an electric separator into three fractions are presented. In this case, when the volume of the grain moth egg increases, it has a longer trajectory. Thus, the third container got conglomerates, the second - large eggs of grain moths, and the first - small ones. It was found that in the third container, where conglomerates should be located, the distribution was: conglomerates $-50 \%$, large eggs $-24 \%$, small eggs $-26 \%$. The penetration of a significant part of large and small grain moth eggs into the third container is explained by the fact that 
the flight path of eggs, when using an electric separator, when compared to pneumatic calibration, is much longer, respectively, the flight speed is higher, so there is more destruction of egg conglomerate ties during the movement to the third container. The second container, where the vast majority were large grain moth eggs, included $40 \%$ of conglomerates, $34 \%$ of large eggs and $26 \%$ of small eggs. The presence of $26 \%$ of small eggs in the second container is explained by the presence of a significant number of conglomerates there, which, as in the third container, when hitting the walls of the hopper, disintegrate forming single grain moth eggs, thus negatively affecting the statistical distribution of the mixture. The first container, where the vast majority should contain small grain moth eggs, contains $30 \%$ of conglomerates, $22 \%$ of large eggs and $48 \%$ of small ones. The obtained results of separation of grain moth eggs suggest the conclusion that it is necessary to pay attention to the dosage of the fraction of eggs that simultaneously enter the electrostatic environment when using an electric separator.

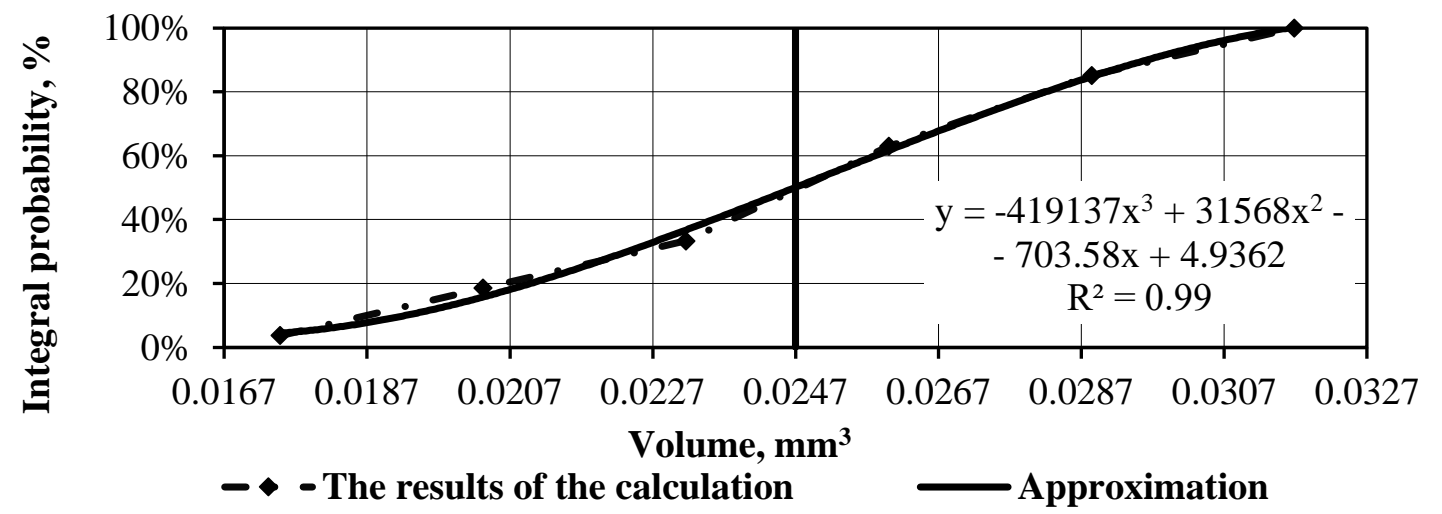

Fig. 3. Integral probability of distribution of grain moth eggs in the second container of the pneumatic calibrator

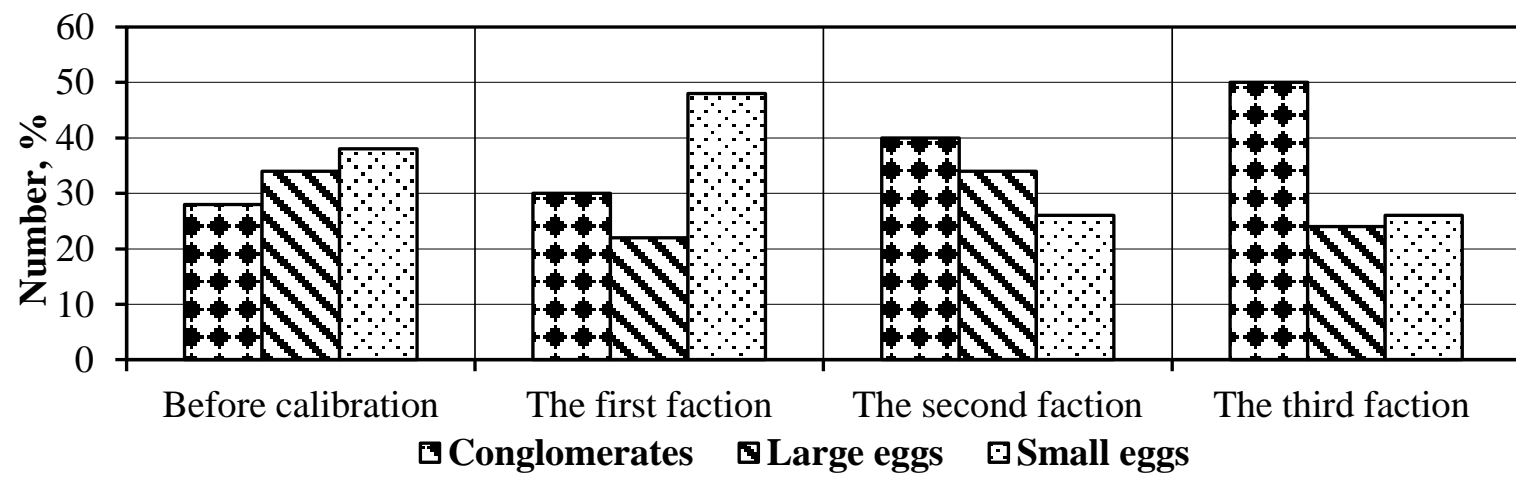

Fig. 4. Diagram of distribution of grain moth eggs after the electric separator

The probability that the volume of grain moth eggs meets the requirements for large eggs in the second container of the electric separator was $55.04 \%$ (Fig. 5).

Fig. 6 demonstrates the results of studies on determining the quality of separation of grain moth eggs by a rotating disk on the outer contour of which there are receiving bins. The results of the study showed that $54 \%$ of conglomerates, $26 \%$ of large and $20 \%$ of small grain moth eggs got into the first container. Getting single grain moth eggs into the first container indicates that during the movement of conglomerates along a rotating disk, the friction force causes them to rotate, which leads to the separation of conglomerates into separate eggs. And since such destruction most likely does not occur at the beginning of the movement of conglomerates, the eggs of the separated grain moth begin to move along their own trajectory. At the same time, the trajectory of their movement is reduced, and they do not have time to get to the second container. The second container, where large grain moth eggs should be, includes $36 \%$ of conglomerates, $38 \%$ of large eggs and $26 \%$ of small ones. The reason for conglomerates entering this container is that conglomerates consisting of two small eggs have the physical and mechanical properties close to large ones and therefore fall into the second container. The third fraction consisted of $20 \%$ of conglomerates, $38 \%$ of large eggs and $42 \%$ of small ones. Reducing 
the speed of rotation of the disk leads to an increase in the number of small grain moth eggs in the second fraction, which will negatively affect the quality of separation.

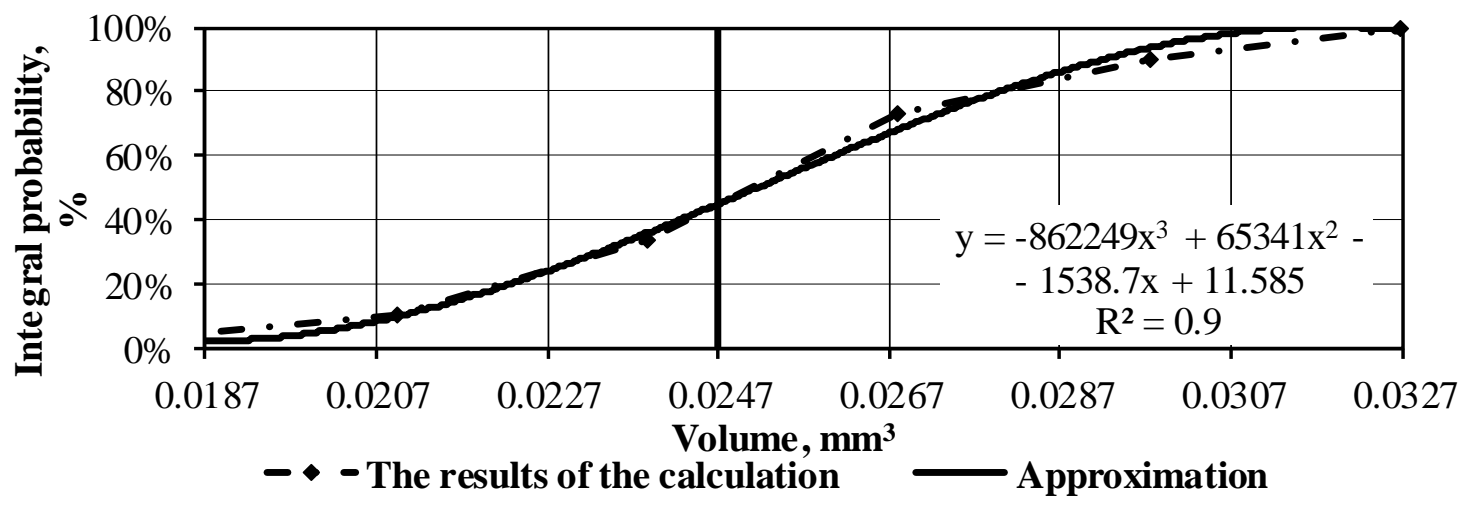

Fig. 5. Integral probability of distribution of single grain moth eggs in the second container of the electric separator

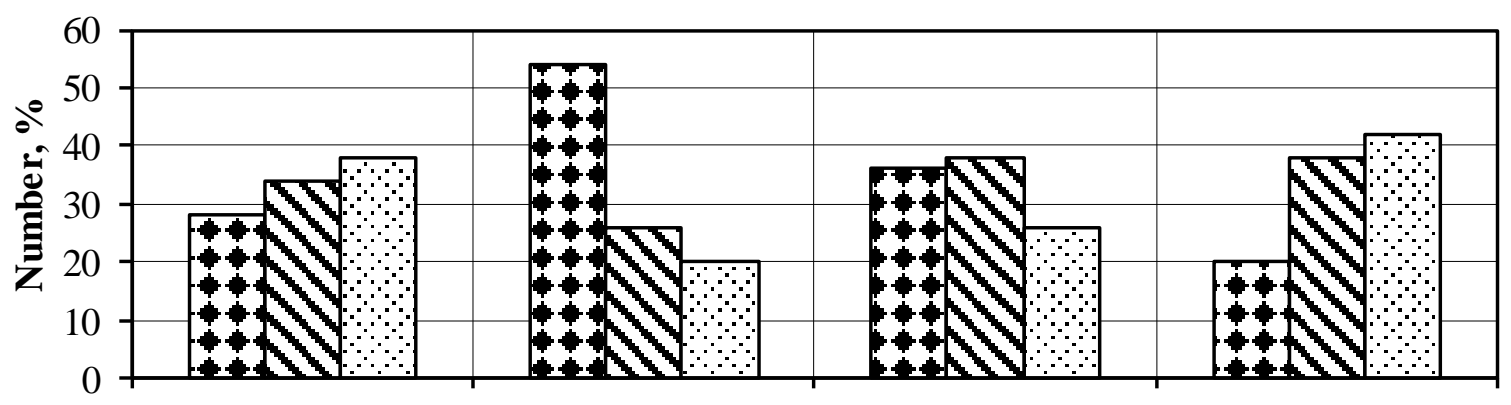

Before calibration The first faction The second faction The third faction ๑ Conglomerates $\square$ Large eggs $\square$ Small eggs

Fig. 6. Diagram of distribution of grain moth eggs after the rotating disk

The probability that the volume of grain moth eggs meets the requirements for large eggs in the second container when the rotating disk is running was $63.54 \%$ (Fig. 7).

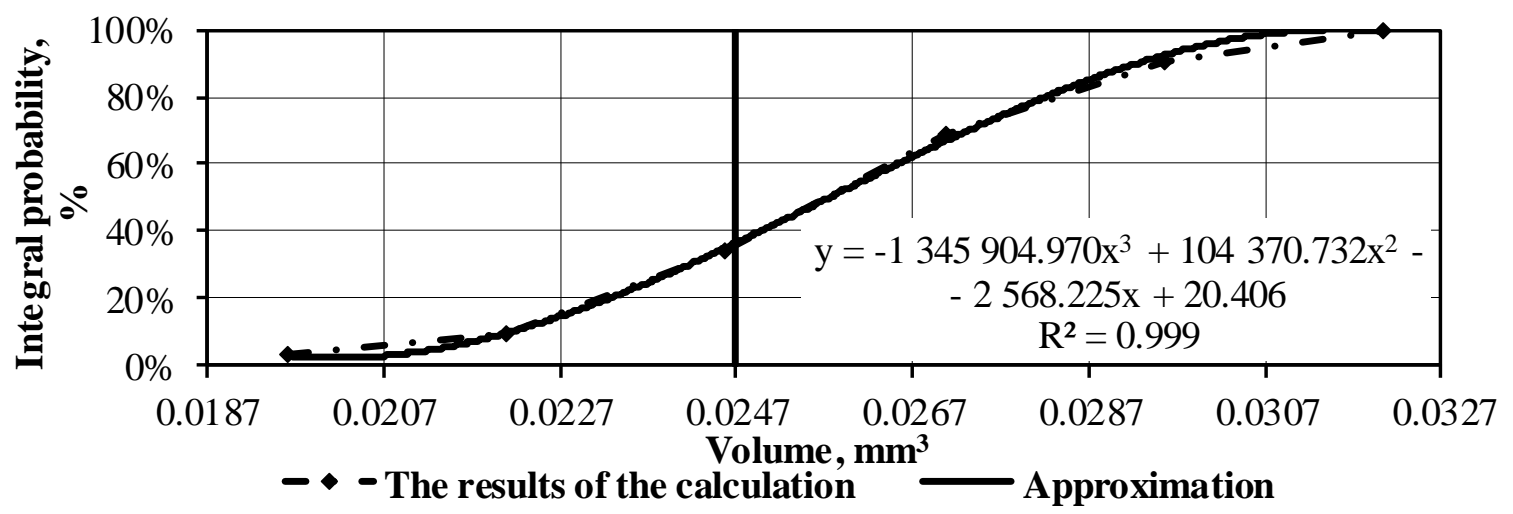

Fig. 7. Integral probability of distribution of individual grain moth eggs in the second container of the rotating disk

Thus, the results of the experimental studies to determine the appropriate method for separating grain moth eggs for production of Trichogramma confirmed that a slight difference in the weight, geometric dimensions, and, respectively, physical and mechanical properties leads to complications in the process of separating eggs into fractions. In addition, the presence of conglomerates in a batch of grain moth eggs leads to a deterioration in the quality of separation, since during separation there is a destruction of the ties and further movement of single eggs with their inappropriate penetration into certain fractions. 
A comparative evaluation of the experimental studies of each method of dividing grain moth eggs into three fractions showed that the separation of conglomerates from the total mass is best performed by a pneumatic calibrator ( $80 \%$ of conglomerates fell into the first fraction). An electric separator and a rotating disk provided less than $60 \%$ of conglomerates to the first fraction. The entry of large grain moth eggs into the second fraction is best provided by a rotating disk $-38 \%$, when using an electric separator and a pneumatic calibrator, $34 \%$ and $26 \%$ of large eggs were obtained, respectively.

The separation of small eggs into the third fraction was best provided by a pneumatic calibrator $70 \%$, and the separation of eggs by other methods was less than $50 \%$. The electric separator demonstrated the worst indicators for dividing grain moth eggs into fractions.

\section{Conclusions}

1. A slight difference in the weight and geometric dimensions leads to a complication of the process of separating eggs into fractions, and the presence of conglomerates in the batch of eggs of grain moths leads to a deterioration in the quality of separation.

2. The results of the experimental studies showed that the integral probability of obtaining large grain moth eggs in the second container of a pneumatic calibrator was $49.9 \%$, an electric separator $55.04 \%$, and a rotating disk $-63.54 \%$.

3. Given that large grain moth eggs are best selected by a rotating disk, and conglomerates are best selected by a pneumatic calibrator, it is necessary to combine them by creating a two - stage calibrator (first select conglomerates with a pneumatic calibrator, and then separate large and small grain moth eggs with a rotating disk).

\section{References}

[1] Marus O., Golub G., Chuba V. Investigation of influence of calibration of grain moth eggs on production of trichogramma for biological protection of plants. Proceedings of the 19 International Scientific Conference Engineering for Rural Development, May 20-22, 2020, Jelgava, Latvia, pp. 1621-1626.

[2] Wang Z.Y., He K.L., Zhang F. etc. Mass rearing and release of Trichogramma for biological control of insect pests of corn in China. Biological Control, vol. 68, 2014, pp. 136-144.

[3] Waage J.K., Lane J.A. The Reproductive Strategy of a Parasitic Wasp: II. Sex Allocation and Local Mate Competition in Trichogramma evanescens. The Journal of Animal Ecology, vol. 53(2), 1984, pp. 417-426.

[4] Greenberg S.M., Legaspi J.C. etc. 1998. Evaluation of Trichogramma spp. (Hymenoptera: Trichogrammatidae) against two pyralid stemborers of Texas sugarcane. Journal of Entomological Science, vol. 33(2), 1998, pp. 158-164.

[5] Oliveira C.M., Oliveira J.V., Barbosa D.R.S. etc. Biological parameters and thermal requirements of Trichogramma pretiosum for the management of the tomato fruit borer (Lepidoptera: Crambidae) in tomatoes. Crop Protection, vol. 99, 2017, pp. 39-44.

[6] Edwin E., Vasantha-Srinivasan P., Ponsankar A. etc. Effects of temperature and nonionizing ultraviolet radiation treatments of eggs of five host insects on production of Trichogramma chilonis Ishii (Hymenoptera: Trichogrammatidae) for biological control applications. Journal of AsiaPacific Entomology, vol. 19, 2016, 1139-1144.

[7] Golub G., Marus O. Determining the influence of the size of grain moth eggs on Trichogramma evanescens indicators. Journal of Plant Protection Research, vol. 61 (1), 2021, pp. 1-10.

[8] Golub G., Marus O., Chuba V. Parameters of pneumatic calibrator of grain moth eggs for Trichogramma production. Scientia agriculturae bohemica, vol. 50 (2), 2019, pp. 117-126.

[9] Голышин Н.M. Методические указания по промышленному производству трихограммы на биофабриках. Всесоюзный научно - исследовательский институт биологических методов защиты растений (Methodical instructions for the industrial production of trichograms at biofactories. All-Union Scientific Research Institute of Biological Methods of Plant Protection). Moscow: Science, 1983, 76 p. (In Russian) 